\title{
In situ neutron diffraction under high pressure - providing an insight into working catalysts
}

\author{
T. Kandemir ${ }^{a}$, D. Wallacher ${ }^{\text {b }}$, T. Hansen ${ }^{\text {c }}$, K.-D. Liss ${ }^{\text {d }}$, R. Naumann d'Alnoncourt ${ }^{\text {a }}$, \\ R. Schlögl ${ }^{\text {a }}$, M. Behrens ${ }^{\text {a,* }}$ \\ ${ }^{a}$ Fritz-Haber-Institut der Max-Planck-Gesellschaft, Faradayweg 4-6, 14195 Berlin, Germany \\ ${ }^{\mathrm{b}}$ Helmholtz-Zentrum Berlin, Hahn-Meitner-Platz 1, 14109 Berlin, Germany \\ ${ }^{c}$ Institut Laue-Langevin, 6 rue Jules Horowitz, 38042 Grenoble, France \\ ${ }^{d}$ The Bragg Institute, ANSTO, New Illawarra Road, Lucas Heights, NSW 2232, Australia \\ *Corresponding author: e-mail behrens@fhi-berlin.mpg.de,
}

Received: 16 November 2011; Available online: 20 January 2012; Published: 1 May 2012

\begin{abstract}
In the present work the construction and application of a continuous flow cell is presented, from which neutron diffraction data could be obtained during catalytic reactions at high pressure. By coupling an online gas detection system, parallel structure and activity investigations of working catalysts under industrial relevant conditions are possible. The flow cell can be operated with different feed gases in a wide range from room temperature to $330^{\circ} \mathrm{C}$. Pressures from ambient up to $60 \mathrm{bar}$ are applicable. An exchangeable sample positioning system makes the flux cell suitable for several different goniomter types on a variety of instrument beam lines. Complementary operational test measurements were carried out monitoring reduction of and methanol synthesis over a $\mathrm{Cu} / \mathrm{ZnO} / \mathrm{Al}_{2} \mathrm{O}_{3}$ catalyst at the high-flux powder diffraction beamline D1B at ILL and high-resolution diffraction beamline Echidna at ANSTO.
\end{abstract}

Keywords: In situ characterization; Heterogeneous catalysis; High-pressure sample environment; Structure-activity correlation

\section{Introduction}

Nowadays catalyst are considered as dynamic materials whose active centres can be formed or transformed due to the chemical potential of reactants or products under reaction conditions. If such changes are reversible, application of in situ methods is needed to study catalysts in their working state to gain a general understanding of structureactivity relationships. It is especially attractive to bridge the so called 'pressure gap' and to go to pressure ranges beyond Ultra-High-Vacuum to ambient pressure regimes. Unfortunately, not many in-situ techniques can be operated at high pressures above ca. 50 bar and allow a direct observation of the working catalyst under realistic chemical potentials as are present in industrial reactors. It often remains questionable, if the properties of model catalysts studied at low pressure can be extrapolated to real catalyst under industrial reaction conditions. Due to their high penetration depth, neutrons allow application of complex sample environment as is needed to study commercial catalyst under industrial reaction conditions, e.g. elevated temperatures and high pressures (up to 60 bar) under strongly reducing gaseous atmospheres like hydrogen/ deuterium-rich synthesis gas. Furthermore neutron diffraction is a powerful tool to study structural and microstructural properties of a catalyst (phaseidentification, strain, particle size, alloy formation, phase transformations) in operation. A lot of technical effort was made by Turner et al. [1] and Walton et al. [2] to study catalyst or related materials under demanding reaction conditions; but still far away from typical industrial conditions. In this present contribution a reaction setup will be presented, which allows carrying out in situ neutron diffraction studies on various catalyst systems under industrial relevant synthesis conditions.

\section{Apparatus design}

Aim of the apparatus design was to build a safe reactor, which allows collecting structural data of a working catalyst under industrially relevant conditions with neutron di_ raction and a parallel monitoring of the product gas stream by mass spectroscopy to correlate structural and catalytic properties. 


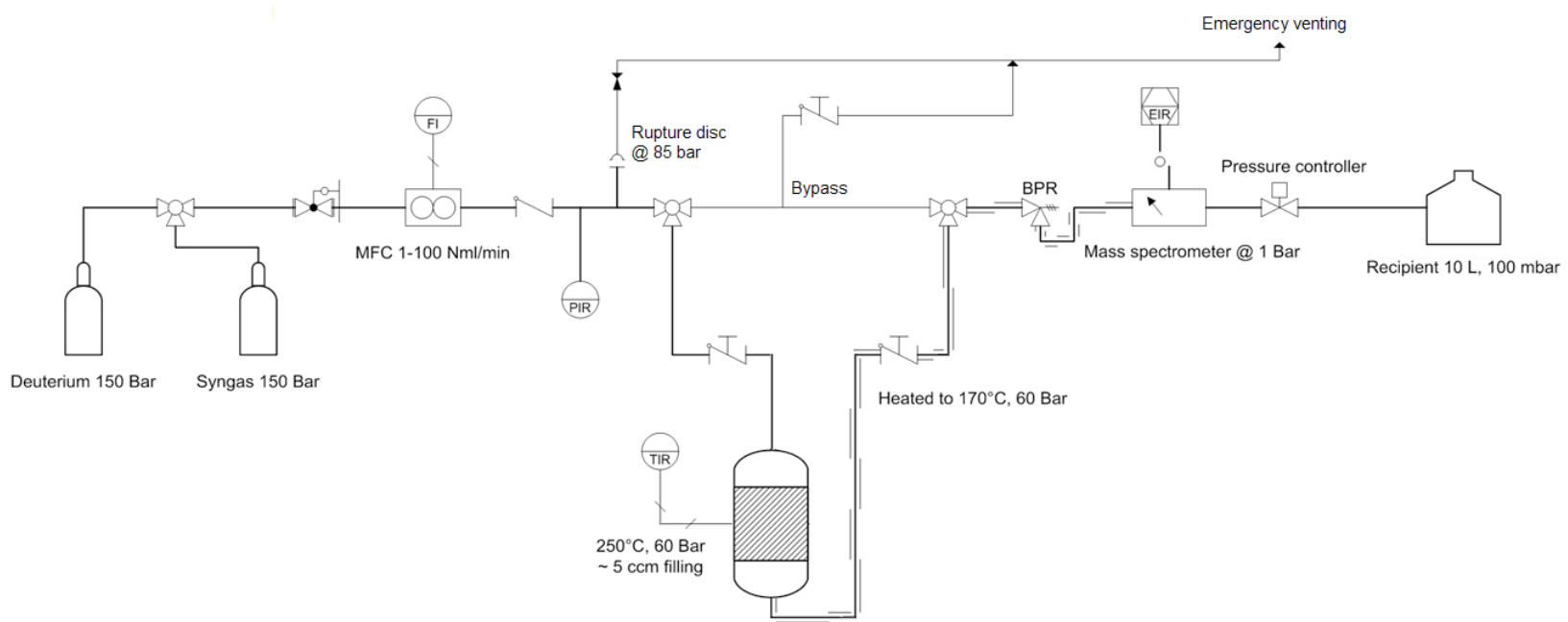

Figure 1: Process flow chart of operating reactor including gas supply and effluent analytics. The system is kept under high pressure until the back pressure regulator (BPR). Gas analytics is carried out under ambient pressure.

The apparatus consists of three basic components: The flow cell including the heated reactor body, the gas supply and the effluent gas analytics.

\subsection{Flow cell and reactor body}

The operation of a flow cell under high pressure is devoted to strict safety regulations. According to these regulations, a bursting of the cell walls should be excluded at any time of the operation. The most critical point is the balance in between finding a material, which shows a moderate coherent scattering behavior on the one hand and is resistant to high pressures of reactive gases like hydrogen, deuterium or carbon monoxide at elevated temperatures on the other hand. Most common materials used in the nuclear branch like vanadium and zircalloy show hydrogen embrittlement and/ or intragranular corrosion [3], if they are operated under high pressures on a long term scale. Especially under alternating high pressure cycles, which occur in insitu conditions a high tensile yield strength of the material must be guaranteed. We have decided to fabricate the cell from thick-walled aluminum-magnesium (AlMg3) offering suffcient pressure and chemical resistance, low absorption and activation and still acceptable coherent scattering. The tubular flux cell was manufactured from a $\mathrm{AlMg} 3$ rod with a nominal outside diameter of $20 \mathrm{~mm}$ and a tensile yield strength of $283 \mathrm{~N} \mathrm{~mm}^{-2}$ at room temperature. Using a lathe, the outer diameter was reduced to $19,05 \mathrm{~mm}$ and a hole with a diameter of $10 \mathrm{~mm}$ was set through, which leaded to a effective wall thickness of $4,52 \mathrm{~mm}$. Strain calculations by assuming a tensile yield strength of $98 \mathrm{~N} \mathrm{~mm}^{-2}$ at $300^{\circ} \mathrm{C}$ and a increased safety factor of 3,6 [4] have shown, that the tube is resistant up to the conditions of 140 bar at $300^{\circ} \mathrm{C}$. Static load tests of the setup have been successfully conducted at 90 bar and $100^{\circ} \mathrm{C}$ for $2 \mathrm{~h}$ and the limits for flow operation has be set to $60 \mathrm{bar}$ at $330^{\circ} \mathrm{C}$. The total length of the tubular reactor was $150 \mathrm{~mm}$ and the catalyst bed bathing in the neutron beam can have a length of up to $70 \mathrm{~mm}$ resulting in a volume of up to $5,5 \mathrm{~cm}^{3}$. To achieve high intensity of the neutron diffraction patterns at short counting times, large sample sizes are required. The cell can be loaded with variable sample amounts from approximately $5 \mathrm{~g}$ to $20 \mathrm{~g}$. The loaded catalyst bed is fixed by quartz wool plugs, which are inserted from both ends. A thermocouple which is inserted from the top allows measuring the bed temperature in the core of the catalyst bed during the reaction. Reactant feed is injected from the top, product stream flows out at the bottom. Both ends of the tube are supported by crimped stainless steel adapting sleeves to assure a selftightening seal. By inserting the end of the flux cell into Swagelok ${ }^{\mathrm{TM}}$ stainless steel (SS 316) 3/ 4 to $1 / 4$ inch reducing unions the cell material forms a tight seal in between the adapting sleeves and the inner mating tape of the reducing unions by its larger thermal expansion coeffcient at $250^{\circ} \mathrm{C}$.

The body of the reactor is also made of AlMg3, due to its good heat capacity and corrosion resistance. If the incident neutron beam is poorly collimated, the reactor body shows low activation behavior and shows a good radiation damage resistance [5]. Given that the body is made out of the same material as the flux cell itself, it is practically seamless on the diffraction pattern. Pedestras and sampling base plate are made out of SS316 and fixed with screws via threading. Six heating cartridges are inserted into holes in the reactor body with a total heating power of $600 \mathrm{~W}(2 \mathrm{x} 150 \mathrm{~W}, 4 \mathrm{x}$ $75 \mathrm{~W}$ ), enabling heating rates of up to $5 \mathrm{~K} \mathrm{~min}^{-1}$. Each heating element is equipped with a thermocouple to check its heating behavior for linearity and overheating. Loading of the filled flow cell is performed by removing the frontal heating covers and inserting the cell into the notch. The installed system with a total weight of 


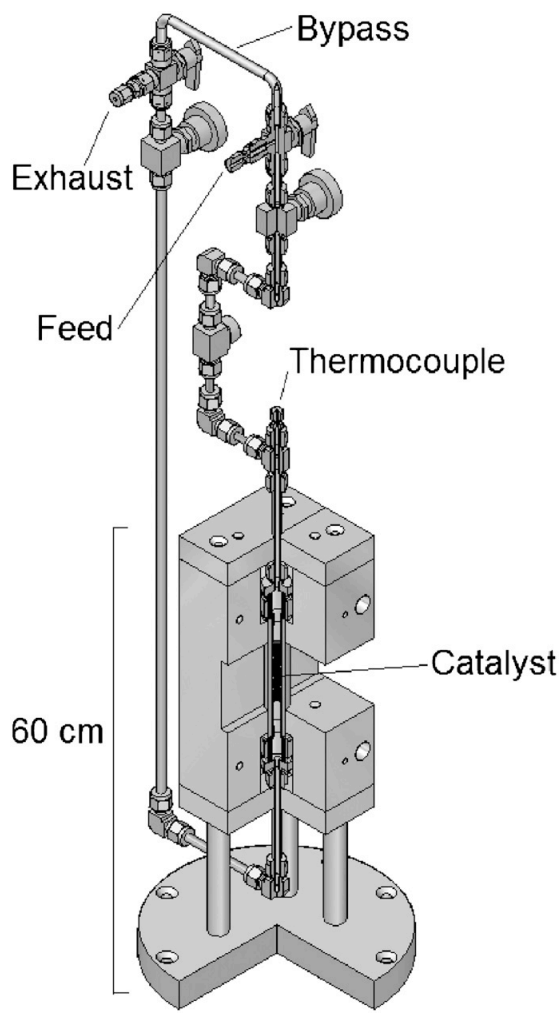

Figure 2: Assembled flow cell inserted into the reactor body

7,5 kg shows high temperature stability. An insulating cover and a convection-reducing thin $\mathrm{Al}$ shielding before the opening of the reactor body allows more effcient heating and more isothermal temperature profiles across the reactor. In case of potential power interruption the initial temperature loss is only $2 \mathrm{~K}$ in 5 minutes. Safety precautions against over-heating are realized by implementing a bimetallic-type thermostat into the current circuit of the heating elements, which cuts of the power at a predefined temperature limit. The flux cell is equipped with a bypass to allow a proper purging of the lines at atmospheric pressure, which is important to avoid oxidation of the catalyst or local explosive atmospheres from residual air in the lines. The schematic process flow chart of the cell system is shown in Fig. 1, the detailed assembly of the reactor is shown in Fig. 2.

\subsection{Gas supply}

The lines of the feed gas supply are set under high pressure by a back pressure regulator (Tescom 44-1100) at the end of the product line. The pressurized gas lines are made of 1/8 and 1/4 inch stainless steel (SS316) tubing and connected with Swagelok couplings, fittings and reducing unions. The flow of the premixed syngas mixture (which had to be supplied at a pressure of ca. 70 bar to achieve a stable outlet pressure of 60 bar) was dosed using a mass flow controller (Brooks 5866) which was able to set a flow

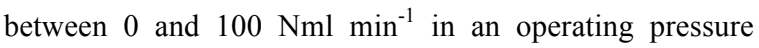

range from 0 to $100 \mathrm{bar}$. The system pressure was electronically measured with an Endress + Hauser PMP 131 pressure transducer which was connected to a Schwille SPE 670 digital display and linked with a serial cable to a Labview application which allowed automated read-out and data-recording. For additional safety reasons a rupture disk with a specified relief pressure of 85 bar and a check valve was installed between the outlet after the pressure transducer and the reactor inlet, which was able to shut down the

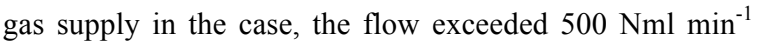
(e.g. in a case of a rupture). The pressurized product lines can be heated to $150^{\circ} \mathrm{C}-170^{\circ} \mathrm{C}$ to avoid condensation of products like steam.

\subsection{Effluent gas analytics}

Gas analytics is performed online at the heated product line beyond the back pressure regulator at atmospheric pressure. By switching the gas flow between bypass or reactor cell, the syngas composition or the effluent gas from the reactor can by analyzed (e.g. for calibration). A gas chromatograph or a mass spectrometer can be coupled to the system. We have used the latter on site during the in situ experiments and the former in the laboratory to quantitatively study the system at the same conditions. During the neutron diffraction experiments a Pfeiffer Vacuum ThermoStar Mass spectrometer was used to check the progress of catalyst activation and whether the expected outlet gas composition was reached. Effluent gases could be collected after online analysis in a condenser vessel or released into the venting system of the neutron facility.

\section{Application example: Methanol synthesis}

A prominent example for the importance of in-situ characterisation of structure-activity relationship in heterogeneous catalysis is the methanol synthesis over $\mathrm{Cu} /$ $\mathrm{ZnO} / \mathrm{Al}_{2} \mathrm{O}_{3}$ catalysts. Even though these catalyst (in different compositions) have been used in commercial methanol synthesis for 45 years, the so-called synergy of $\mathrm{Cu} / \mathrm{ZnO}$ is still under debate in literature. Several models have been introduced [6] which should give a first approach to properties of operating industrial catalyst systems. Some of the observations made on this system like brass formation, dynamical undergoing of morphological changes [7] have been directly obtained only on model catalysts under conditions, where no methanol has been produced. In the present work, the structural properties of the aforementioned industrial catalyst under realistic industrial synthesis conditions is studied using the flow cell reactor system described above. To minimize the effect of incoherent scattering, hydrogen was replaced by deuterium in the reaction gases. 


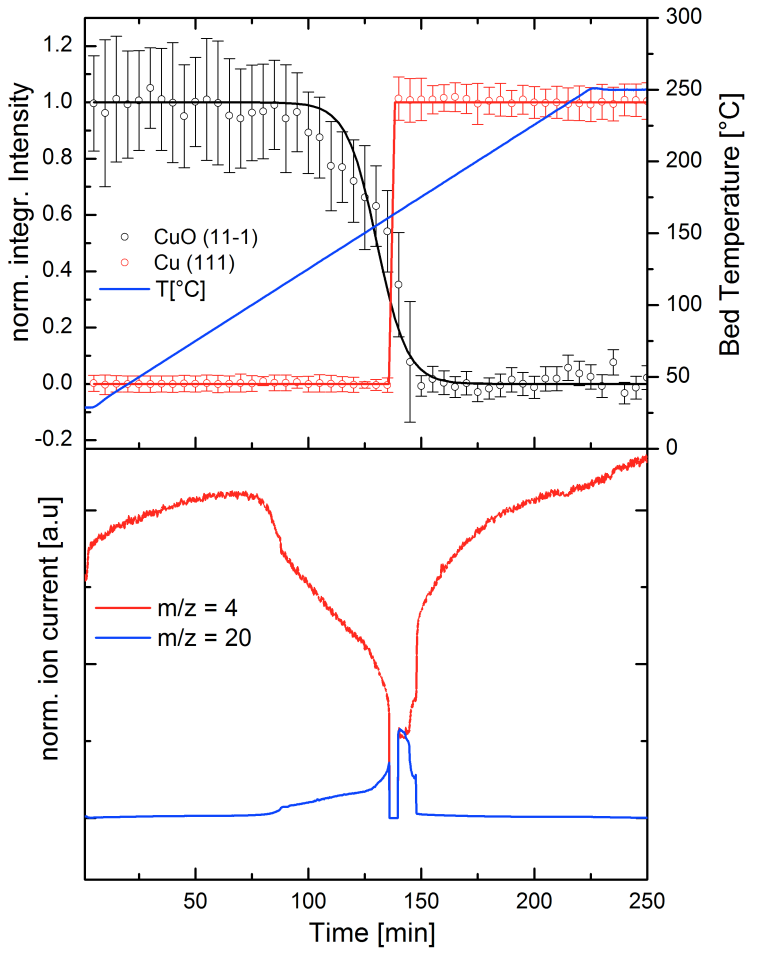

Figure 3: Reduction procedure of a commercial $\mathrm{CuO} / \mathrm{ZnO} / \mathrm{Al}_{2} \mathrm{O}_{3}$ catalyst. Normalized integrated intensities of the $\mathrm{CuO}(11-1)$ and $\mathrm{Cu}(111)$ peaks correlated with the catalyst bed temperatur (top) and effluent gas composition (bottom) during isobar reduction from $28^{\circ} \mathrm{C}$ to $250^{\circ} \mathrm{C}$ in $\mathrm{D}_{2}$ feed. Missing ion-current between 130 $\mathrm{min}$ and $140 \mathrm{~min}$ is devoted to a artefact.

\subsection{Catalyst activation in high-flux diffraction}

Due to their pyrophoric nature, nano-structured $\mathrm{Cu}$ / $\mathrm{ZnO} / \mathrm{Al}_{2} \mathrm{O}_{3}$ catalysts are handled in their completely oxidized form, i.e. as $\mathrm{CuO} / \mathrm{ZnO} / \mathrm{Al}_{2} \mathrm{O}_{3}$, and the first step of a methanol synthesis experiment is the activation of the catalyst by reduction of the $\mathrm{CuO}$ component to metallic $\mathrm{Cu}$ :

$$
\mathrm{CuO} / \mathrm{ZnO} / \mathrm{Al}_{2} \mathrm{O}_{3}+\mathrm{D}_{2} \rightarrow \mathrm{Cu} / \mathrm{ZnO} / \mathrm{Al}_{2} \mathrm{O}_{3}+\mathrm{D}_{2} \mathrm{O}
$$

To study the phase evolution during reduction a commercial $\mathrm{CuO} / \mathrm{ZnO} / \mathrm{Al}_{2} \mathrm{O}_{3}$ catalyst the beamline $\mathrm{D} 1 \mathrm{~B}$ at ILL in Grenoble was used. While requesting the highest available neutron flux for a suffcient time resolution of the experiment, a focusing highly ordered pyrolitic graphite monochromator was used, to get a wavelenght of $\lambda=2,52 \AA$, which lead to an effective flux of $6,5 \times 10^{6} \mathrm{n} \mathrm{cm}^{-2} \mathrm{~s}^{-1}$ at the sample [8]. By setting the $3 \mathrm{He} / \mathrm{Xe}$ position-sensitive detector to a take-off angle of $45,06^{\circ}$ the angular range up to $124,86^{\circ} 2 \theta$ (corresponding Q-range $1,91 \AA^{-1}$ to $4,2 \AA^{-1}$ ) was covered. The reduction of $6 \mathrm{~g}$ catalyst was carried out with a feed stream of $100 \mathrm{Nml} \mathrm{min}^{-1}$ pure $\mathrm{D}_{2}$, bed temperature was ramped from $28^{\circ} \mathrm{C}$ at $1 \mathrm{~K} \mathrm{~min}^{-1}$ to $250^{\circ} \mathrm{C}$ at ambient pressure. Effluent gas composition was tracked by mass spectroscopy from mass 0 to 50 in analog scan mode; the probing cycle was 11 second per spectrum. During the reduction procedure 250 patterns were acquired with an acquisition time of $5 \mathrm{~min}$ per pattern. The patterns were normalized to monitor counting rate. Afterwards the intensities of the $\mathrm{CuO}(11-1)$ at $\mathrm{Q}=2,4925 \AA^{-1}$ and $\mathrm{Cu}(111)$ at $\mathrm{Q}=$ $3,0122 \AA^{-1}$ peaks were fitted using a pseudo-Voigt peak shape function. After normalizing them to the highest intensity they were plotted on an absolute timescale. The normalized integrated intensities of the $\mathrm{Cu}(111)$ and $\mathrm{CuO}(11-1)$ peaks are correlated to the catalyst bed temperature and the effluent gas composition in Fig. 3.

\subsection{Working catalyst in high-resolution diffrac- tion}

High-resolution di_ raction was performed on ECHIDNA at ANSTO by using a Ge(335) monochromator at a angle of $70^{\circ}$, giving a highly collimated beam at a wavelength of $\lambda=1,622 \AA$. A large array of 128 position sensitive $3 \mathrm{He}$ detectors allowed to cover a angular range of $4^{\circ}<2^{\circ}<164^{\circ}$ which correspondents to a Q-range of $0,28 \AA^{-1}$ to $7,7 \AA^{-1}[9][10]$. The reduction of the catalyst was carried out on-site at the diffraction experiment under the same conditions as in the highflux experiment. After reaching the temperature plateau at $250^{\circ} \mathrm{C}$, the feed is switched to syngas consisting of $\mathrm{D}_{2}, \mathrm{CO}_{2}, \mathrm{CO}$ and $\mathrm{Ar}$ as internal standard and the flow cell is pressurized by the back pressure regulator with a rate of $0,78 \mathrm{bar}^{\mathrm{min}^{-1}}$. The methanol synthesis reaction, formally according to

$$
\mathrm{CO}_{2}+3 \mathrm{D}_{2} \rightarrow \mathrm{CD}_{3} \mathrm{OD}+\mathrm{D}_{2} \mathrm{O}
$$

was conducted in thermodynamic equilibrium at $250^{\circ} \mathrm{C}$ and 60 bar. After reaching stable operating conditions the effluent gas composition is monitored by mass spectrometry. At stable equilibrium composition of the effluent gas, diffraction patterns with 1 or 2 hours acquisition time were recorded. The observed intensities in the monitor- and effciency normalized patterns were evaluated by multiple peak-fitting to account for sample and cellmaterial contributions.

\section{Results}

With increasing temperature the reduction of the $\mathrm{CuO}$ containing precursor phase is initiated around $115^{\circ} \mathrm{C}$ and finishes at $186^{\circ} \mathrm{C}$. Metallic $\mathrm{Cu}$ appears in the diffraction pattern at $164^{\circ} \mathrm{C} . \mathrm{D}_{2}$ consumption starts around $100^{\circ} \mathrm{C}$ and ends in a regime, were $\mathrm{CuO}$ is completely reduced. Additionally to the moderate angular resolution of D1B, the poor crystallinity of all component in the nano-structured catalysts, in particular of $\mathrm{ZnO}$ and $\mathrm{Al}_{2} \mathrm{O}_{3}$ contributes to a relatively high background, which leads to a larger uncertainty of the low-intensity and broad peaks of $\mathrm{CuO}$ compared to the more crystalline metallic $\mathrm{Cu}$. Complete 


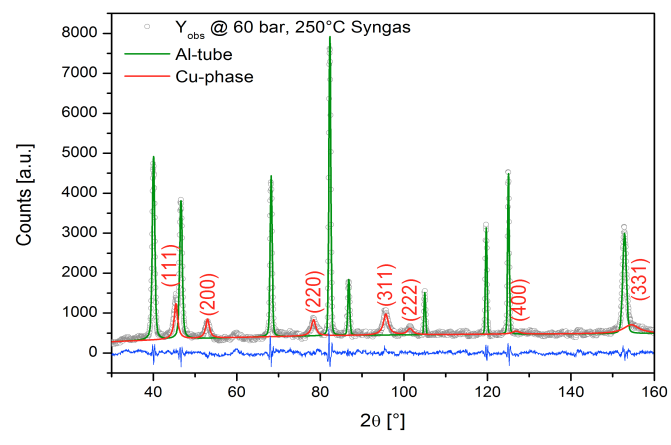

Figure 4: Neutron powder diffraction pattern of a working commercial $\mathrm{CuO} / \mathrm{ZnO} / \mathrm{Al}_{2} \mathrm{O}_{3}$ catalyst under syngas at $250^{\circ} \mathrm{C}$ and 60 bar.

conversion of $\mathrm{D}_{2}$ was reached within the maximum of $\mathrm{D}_{2} \mathrm{O}$ desorption in coincidence with metallic $\mathrm{Cu}$ evolution, which is in good accordance with literature [11]. No indication of intermediate formation of crystalline $\mathrm{Cu}_{2} \mathrm{O}$ has been observed in the diffraction patterns, but the asymmetric shape of the curves in Fig. 3 and the inception at a normalized intensity $>0.5$ suggest the presence of a undetected, probably amorphous intermediate, which may be a form of $\mathrm{Cu}(\mathrm{I})$-oxide. Fig. 4 shows a diffraction pattern of a commercial $\mathrm{CuO} / \mathrm{ZnO} / \mathrm{Al}_{2} \mathrm{O}_{3}$ catalyst in operation under $250^{\circ} \mathrm{C}$ and 60 bar pressure. Strong diffraction peaks from the cell material can be seen and are highlighted with green profiles. The peaks of the catalytically active copper phase of the catalyst (red profile) can be clearly distinguished and indexed. The scattered intensities are fitted by a pseudoVoigt peak shape function for further evaluation. Such patterns can serve as a starting point to investigate the

\section{References}

[1] J. F. C. Turner, R. Done, J. Dreyer,W. I. F. David, C. R. A. Catlow, On apparatus for studying catalysts and catalytic processes using neutron scattering, Review of Scientific Instruments 70 (5) (1999) 2325-2330.

[2] R. I. Walton, R. J. Francis, P. S. Halasyamani, D. O. Hare, R. I. Smith, R. Done, R. J. Humphreys, Novel apparatus for the in situ study of hydrothermal crystallizations using timeresolved neutron diffraction, Review of Scientific Instruments 70 (8) (1999) 3391-3396.

[3] H. Matsui, Hydrogen Embrittlement in Vanadium and Niobium, Tech. rep., 1774th report of The Research Institute for Iron, Steel and Other Materials (1984).

[4] DIN EN 13480-3/A1:2005 Metallic industrial piping Part3: Design and calculation (2005).

[5] D. Hamaguchi, Y. Dai, Microstructural change in $\mathrm{AlMg}_{3}$ alloy irradiated by spallation neutrons and high energy protons, Journal of Nuclear Materials 329-333 (Part 2) (2004) 958 - 962, proceedings of the 11th International Conference on Fusion Reactor Materials (ICFRM-11). structural answer of a working catalyst to variation of the reaction conditions and to correlate such changes to catalytic performance. More detailed results of the methanol synthesis catalysts will be published elsewhere.

\section{Discussion}

A flow cell for in-situ neutron diffraction during continuous catalytic experiments under high pressure was designed and constructed. It was successfully tested for catalyst activation and methanol synthesis over $\mathrm{CuO} / \mathrm{ZnO} / \mathrm{Al}_{2} \mathrm{O}_{3}$ under equilibrium conditions at $250^{\circ} \mathrm{C}$ and 60 bar while obtaining structural information of the catalyst. Online effluent gas analytics allows direct correlation of structural properties with catalytic activity. Although there is a strong scattering signal from the flow cell wall material, the structural signature of the investigated catalytic system is strong enough to give detailed results concerning the crystal- and microstructure of a catalyst under industrially relevant reaction conditions.

\section{Acknowledgements}

The authors would like to thank Michael Tovar, Alain Daramsy, Scott Olsen, Eugen Stotz, Edward Kunkes and Gregor Wowsnick for technical, DFG (German research foundation) for financial support (BE 4767/ 1-1). Süd-Chemie AG is acknowledged for providing the catalyst and ILL and ANSTO for allocation of beamtime.

[6] J. B. Hansen, P. E. H. Nielsen, Methanol Synthesis, WileyVCH Verlag GmbH \& Co. KGaA, 2008.

[7] P. L. Hansen, Atom-Resolved Imaging of Dynamic Shape Changes in Supported Copper Nanocrystals, Science 295 (2002) 2053.

[8] I. P. Orench, J. A. R. Velamazn, J. Campo, The Spanish CRG Instruments at ILL: Historical Perspective and Future Developments, Neutron News 21 (3) (2010) 20-23.

[9] K.-D. Liss, B. Hunter, M. Hagen, T. Noakes, S. Kennedy, Echidna-the new high-resolution powder diffractometer being built at OPAL, Physica B: Condensed Matter 385-386 (2006) 1010 - 1012 .

[10] M. Avdeev, J. R. Hester, V. K. Peterson, A. J. Studer, Wombat and Echidna: The Powder Diffractometers, Neutron News 20 (4) (2009) 29-33.

[11] J. A. Rodriguez, J. Kim, J. Hanson, M. Prez, A. I. Frenkel, Reduction of $\mathrm{CuO}$ in $\mathrm{H}_{2}$ : In Situ Time-Resolved XRD Studies, Catalysis Letters 85 (2003) 247-254. 